МОДЕЛИРОВАНИЕ ПОДКОЖНОГО КСЕНОГРАФТА МЕЛАНОМЫ КОЖИ ЧЕЛОВЕКА МЕL СНЕR С МУТАЦИЕЙ V600Е ВRАF НА ИММУНОДЕФИЦИТНЫХ МЫШАХ ДЛЯ ДОКЛИНИЧЕСКОГО ИЗУЧЕНИЯ ТАРГЕТНЫХ ПРОТИВООПУХОЛЕВЫХ СРЕДСТВ

\author{
Н.В. Андронова, Л.Ф. Морозова, И.Н. Михайлова, А.А. Лушникова, Д.А. Понкратова, \\ Н.Т. Райхлин, И.А. Букаева, Ю.А. Борисова, С.М. Ситдикова, Е.М. Трещалина \\ ФГБУ «Российский онкологический научный центр им. Н.Н. Блохина» Минздрава России; \\ Россия, 115478 Москва, Каширское шоссе, 24
}

Контакты: Сурия Мансуровна Ситдикова suriyasitdikova@yandex.ru

Введение. Разработка новых моделей диссеминированной меланомы кожи человека с молекулярно-генетической мишенью для таргетной терапии повышает результативность доклинических исследований іп vitro и іп vіvо новых антимеланомных средств и их комбинащий. Такая возможность реализована путем адаптации к росту іп vіvо оригинальной линии клеток пигментированной меланомы кожи человека теl Cher и получения подкожного $(\mathrm{n} / \kappa)$ ксенографта под контролем трансплантационных, морфологических, молекулярно-генетических (мутация V600E BRAF) и химиотерапевтических (чувствительность к ингибитору ВRAF-киназ вемурафенибу) характеристик.

Цель исследования - получение из линии клеток теl Cher $n / \kappa$ ксенографта пигментированной меланомы кожи человека с мутацией V600E BRAF, чувствительной к специфической таргетной терапии.

Материалы и методы. Использованы линия клеток пигментированной меланомы кожи человека теl Сhег из коллекции ФГБУ «Российский онкологический научный центр им. Н.Н. Блохина» Минздрава России (РОНЦ) и иммунодефицитные мыши-сам$\kappa и$ Balb/c пиде разведения РОНЦ. Искомые характеристики определены при многократном $n / \kappa$ трансплантировании іп vіvо с помощью методов трансплантационной биологии, световой микроскопии, молекулярной генетики и экспериментальной химиотерапии. Чувствительность к ингибитору BRAF-киназы вемурафенибу оценена под контролем скорости роста опухоли $\left(V / V_{\partial}\right)$ по адекватным для пациентов показателям: наличие полной ремиссии и возможность рецидив.

Результаты. При $\mathrm{n} / \kappa$ трансплантации $10^{7}$ клеток линии теl Cher получены цитологически идентичные перевиваемые $n / \kappa$ ксенографты с устойчивой кинетикой роста на 4-9-м пассажах (латентная фаза 8 дней, экспоненциальная - до 14, стационарная - до 24) и наличием мутации V600Е BRAF. Вемурафениб в разовой дозе 75 мг/кг вызвал полную ремиссию в течение 15-дневного курса и в течение 7 дней после его отмены, с последующим рецидивом.

Заключение. Полученный из линии клеток пигментированной меланомы кожи человека теl Сhег чувствительный к вемурафенибу $n / \kappa$ ксенографт с мутацией V600E BRAF пригоден для доклинического изучения направленных на эту мишень новых противомеланомных средств.

Ключевые слова: пигментированная меланома кожи человека, мутация V600Е BRAF, подкожный ксенографт, иммунодефицитная мышь

DOI: $10.17650 / 1726-9784-2016-15-4-65-71$

\title{
MODELING OF A SUBCUTANEOUS XENOGRAFT OF HUMAN SKIN MELANOMA MEL CHER WITH V600E BRAF MUTATION IN IMMUNODEFICIENT MICE FOR PRECLINICAL STUDY THE TARGETING ANTICANCER DRUGS
}

\author{
N.V. Andronova, L.F. Morozova, I.N. Mikhailova, A.A. Lushnikova, D.A. Ponkratova, N.T. Raychlin, \\ I.A. Bukaeva, U.A. Borisova, S.M. Sitdikova, H.M. Treshalina
}

N.N. Blokhin Russian Cancer Research Center, Ministry of Health of Russia; 24 Kashyrskoe Shosse, Moscow, 115478, Russia

Introduction. Development of new models of a human disseminated skin melanoma of the with molecular-genetic targets for specific therapy increases productivity of the preclinical researches new the anti-melanoma drugs or their combinations in vitro and in vivo. Such opportunity is realized by adaptation in vivo of the original human pigmented skin melanoma cell line mel Cher and receiving subcutaneous (s. c.) xenograft under monitoring of transplant, morphological, molecular-genetic (V600E BRAF mutation) and chemotherapeutic (sensitivity for the inhibitor of BRAF kinases to a vemurafenib) characteristics. 
Objective: receiving from the cell line mel Cher s. c. xenogratft of the human pigmented skin melanoma with V600E BRAF mutation and sensitive to specific target therapy.

Materials and methods. Human pigmented skin melanoma cell line mel Cher from the Collection of Russian Cancer Research Center and immunodeficient Balb/c nude female mice cultivated in Russian Cancer Research Center was used. Required characteristics are defined by multiple s. c. transplanting in vivo by methods of transplant biology, a light microscopy, molecular-genetics and the experimental chemotherapy. Sensitivity to a BRAF kinase inhibitor to a vemurafenib was estimated under monitoring of the tumor growth rate $(V t / V 0)$ on indexes, adequate for patients: existence of the complete remission and possibility of recurrence.

Results. When s. c. transplantation of 107 cell of mel Cher line cytological identical intertwined s. c. xenografts with a stable growth kinetics on 4-9 passages (a latent phase 8 days, exponential - to 14 days, stationary - to 24 days) and existence of a mutation of V600E $B R A F$ have been recieved. Vemurafenib in a single dose of $75 \mathrm{mg} / \mathrm{kg}$ caused the complete remission during a 15-day course and within 7 days after its cancellation - with the subsequent recurrence.

Conclusion: receiving from the cell line mel Cher s. c. xenogratft of a human pigmented melanoma of skin with a mutation of V600E BRAF and sensitive to specific target therapy is suitable for preclinical studying of the new anti-melanoma drugs specific for this target.

Key words: human pigmented skin melanoma, V600E BRAF mutation, subcutaneous xenograft, immunodeficient mice

\section{Введение}

Меланома кожи человека - гетерогенное по фенотипу и молекулярно-генетическим характеристикам заболевание, диссеминированная форма которого отличается чрезвычайно низкой чувствительностью к различным видам терапии $[1,2]$.

С учетом успехов таргетной терапии диссеминированного процесса приоритетом при создании моделей меланомы на животных остается прогрессия опухоли, развивающейся при наличии мутаций в генах, дефектные продукты которых нарушают клеточную пролиферацию, дифференцировку и апоптоз. Клиническая значимость для антимеланомной терапии доказана для мутации V600Е в 15-м экзоне гена $B R A F$, приводящей к гиперактивации серинтреониновой BRAF-киназы с последующей аномальной пролиферацией клеток и быстрой прогрессией опухоли [3-6].

Для избирательного блокирования BRAF-киназы создан ряд антимеланомных таргетных препаратов, наиболее эффективным из которых при лечении диссеминированной меланомы в клинике и на различных экспериментальных моделях является производное 7-азаиндола вемурафениб (PLX4032, zelboraf $^{\text {тм }}$, зельбораф) $[3,7,8]$. Соответственно наличие доклинической меланомной модели с мутацией V600E BRAF, чувствительной к вемурафенибу, открывает возможность подготовки для клинической апробации новых таргетных антимеланомных лекарственных средств.

Модели in vivo для изучения антимеланомных таргетных препаратов представлены подкожными (п/к) ксенографтами, полученными из клеток метастатической меланомы кожи человека и имеющими специфическую мишень [9]. В Коллекции ФГБУ «Российский онкологический научный центр им. Н.Н. Блохина» Минздрава России (РОНЦ им. Н.Н. Блохина) есть оригинальная клеточная линия меланомы кожи человека mel Cher (№ 704Д в РККК (П)), полученная из удаленного метастатического лимфатического узла пациентки, цитологически полиморфная, со стабильными культуральными, морфологическими и индивидуальными фенотипическими характеристиками (раково-тестикулярный антиген MAGE-3, дифференцировочные антигены CD63, HMW, HMB45 и Tyrosinase, молекулы гистосовместимости 1-го и 2-го класса) $[10,11]$. В рамках этой работы в клеткаx mel Cher выявлена мутация V600E BRAF [5].

Цель исследования - получение подкожных ксенографтов меланомы кожи человека с мутацией V600E BRAF у иммунодефицитных мышей Balb/c nude в качестве доклинической модели.

Задачи исследования:

определение мутации V600Е в 15-м экзоне гена $B R A F$ в клетках mel Cher и в срезах п/к ксенографтов mel Cher;

- адаптация клеточной линии mel Cher к росту in vivo под контролем прививаемости и стабильной кинетики;

- оценка лекарственной чувствительности к вемурафенибу п/к ксенографтов mel Cher.

\section{Материалы и методы}

Мутацию V600Е в 15-м экзоне $B R A F$ определяли в клетках линии mel Cher и в стабильных пассажах п/к ксенографтов 4-го и 9-го пассажей на пике экспоненциальной фазы роста. При выделении ДНК фрагменты опухолевой ткани объемом $\sim 1 \mathrm{~cm}^{3}$ гомогенизировали в лизирующем буфере, содержащем $10 \mathrm{MM}$ Tris-HCl, 2 мМ ЭДТА, 4 мМ NaCl, $\mathrm{pH}=8,0$, и 200 мкл гомогената переносили в пластиковую пробирку

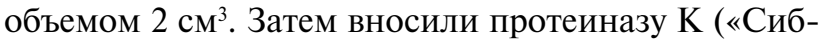
Энзим», Россия) до концентрации 50 мкг/мл и SDS до $0,5 \%$, образец тщательно перемешивали. Содержимое пробирки инкубировали в течение 2 ч при $37^{\circ} \mathrm{C}$. Объем образца доводили до 5 мл стандартным буфером TE, $\mathrm{pH} 8,0$ и последовательно экстрагировали ДНК 
равными объемами фенола, смеси фенол-хлороформ (24: 1) и хлороформом. К образцу добавляли 1/10 объема 5 М ацетата натрия, $\mathrm{pH}$ 5,3, перемешивали и осаждали ДНК путем добавления 2,5 объема охлажденного $96 \%$ этанола, затем оставляли образец на 30 мин при $-20{ }^{\circ} \mathrm{C}$. Пробирку центрифугировали 15 мин при $0{ }^{\circ} \mathrm{C}$ с ускорением 12000 g. Осадок ДНК высушивали на воздухе и растворяли в 100 мкл буфера ТЕ, $\mathrm{pH} 8,0$. Хранили раствор ДНК при $-20^{\circ} \mathrm{C}$. Для поиска соматических мутаций в 15-м экзоне гена BRAF использовали полимеразную цепную реакцию (ПЦР) с праймерами $B R A F \_$Ex15BR - For и $B R A F \_$Ex15BR $\operatorname{Rev}$, температура отжига праймеров $56^{\circ} \mathrm{C}$ :

BRAF_Ex15BR - For 5'-CTACTGTTTTCCTTTA CTTACTACAC-3'

BRAF_Ex15BR_Rev 5'-ATCCAGACAACTGTTC AAACTGATG-3'.

ПЦР проводили в объеме 25 мкл реакционной смеси по известной схеме [11]. Полосу, соответствующую последовательности 15-го экзона гена $B R A F$ длиной 173 п. н., вырезали из геля и выделяли ДНК с помощью набора Wizard ${ }^{\circledR}$ PCR Preps DNA Purification System (Promega, США). Образец ДНК секвенировали на автоматическом секвенаторе ABI PRISM 3100 (Applied Biosystems, США) по протоколам фирмы-производителя в режиме фрагментного анализа. Для оценки результатов ПЦР-анализа использовали компьютерные программы Chromas или GeneMapper.

Для получения п/к ксенографтов использованы 120 половозрелых 6-8- недельных иммунодефицитных мышей обоего пола Balb/c nude конвенционального содержания [12]. Контролем адаптации in vivo и получения стабильных п/к ксенографтов меланомы кожи человека линии mel Cher служили следующие характеристики:

наличие мутации V600E BRAF в клетках линии mel Cher;

- оптимальная прививочная доза клеток, дающая п/к ксенографты у $100 \%$ мышей в группе;

- цитологическая идентичность клеточной линии и п/к ксенографта;

- устойчивая многократная трансплантация (до 9-го пассажа) п/к ксенографта взвесью опухолевой ткани;

- устойчивая кинетика роста п/к ксенографтов;

- гистологическая верификация меланомы кожи человека в п/к ксенографтах;

- наличие мутации V600E BRAF в п/к ксенографтах;

- высокая чувствительность п/к ксенографтов к вемурафенибу.

Инокулятом для имплантации служила культивированная в атмосфере с $\mathrm{CO}_{2}$ клеточная линия меланомы кожи человека mel Cher из коллекции РОНЦ им. Н.Н. Блохина [11]. Отмытые физиологическим раствором от культуральной среды клетки (нулевой пассаж) помещали в питательную среду 199 и имплантировали с использованием стандартной техники перевивки подкожно в дозах $0,6 \times 10^{7} ; 0,8 \times 10^{7}$; $1,0 \times 10^{7}$ клеток на 1 мышь $(n=4)$ в 0,2 мл питательной среды [13]. Все манипуляции с имплантацией клеток опухоли человека выполняли под ламинаром (Lamsystems LS 240.120.00, Россия) с соблюдением соответствующей асептики и антисептики. Контроль прививаемости клеток осуществляли по наличию пальпируемых опухолей у мышей.

Повторную трансплантацию (1-9-й пассажи) выполняли взвесью опухолевой ткани предшествующих пассажей, которую инокулировали мышам $(n=4)$ по 50 мг в разведении 1: 20 питательной средой 199. О кинетике роста п/к ксенографтов судили по результатам измерения в течение 2-4 нед каждые 3-4 дня с помощью электронного штангенциркуля. Период более чем 2-кратного увеличения среднего объема опухоли $\left(\mathrm{V}_{\mathrm{cp}}=\mathrm{a} \times \mathrm{b} \times \mathrm{c}\right)$ определял длительность экспоненциальной фазы роста, а стабилизация роста опухоли на уровне менее 2-кратного увеличения - длительность стационарной фазы роста. Кратность прироста опухоли рассчитывали по соотношению последующего среднего объема к предыдущему $\left(\mathrm{V}_{\mathrm{t}} / \mathrm{V}_{\mathrm{t}-1}\right)$. Отсутствие значимых различий кривых роста опухоли 2 смежных пассажей в полулогарифмической системе координат подтверждало устойчивость кинетических характеристик п/к ксенографтов меланомы кожи человека mel Cher у мышей Balb/c nude.

Цитологическую и гистологическую верификацию п/к ксенографтов для сравнения клеточного состава с исходной клеточной линией меланомы кожи человека mel Cher выполняли стандартно в 9-м пассаже с устойчивой кинетикой роста с помощью световой микроскопии («Поливар», Австрия) срезов опухоли, окрашенных гематоксилином и эозином. Контроль содержания меланина в культуре клеток и опухолевых узлах выполнен визуально по черной или темно-коричневой окраске образца с цито- и гистологическим подтверждением.

Вемурафениб (зельбораф, Rocher, Германия) вводили мышам $(n=10)$ с пальпируемыми п/к ксенографтами меланомы человека mel Cher в эффективной разовой дозе 75 мг/кг ежедневно в желудок на 4-19-е сут после трансплантации [13]. Контроль роста опухоли в динамике осуществляли в этой группе и в равночисленной группе без специфического лечения до начала (нулевые сутки) и 5-кратно после окончания курса вплоть до 31-го дня роста опухоли. Статистический анализ параметров роста п/к ксенографтов во всех случаях проведен с помощью стандартного метода Фишера. Исследования на животных с опухолями выполнены в соответствии с рекомендациями [14]. 
Таблица 1. Показатели роста меланомных узлов (нулевой пассаж) под кожей бока мышей-самок Ваlb/с пиdе после имплантации $1,0 \times 10^{7}$ клеток линии пигментированной меланомы кожи человека теl Cher

\begin{tabular}{|c|c|c|c|c|c|}
\hline \multirow{2}{*}{ Номер мыши } & \multicolumn{5}{|c|}{ Средний объем меланомных узлов после имплантации клеток mel Cher, мм³ } \\
\hline & на 10-е сутки & на 13-е сутки & на 17-е сутки & на 21-е сутки & на 24-е сутки \\
\hline 1 & 48 & 80 & 108 & 72 & 104 \\
\hline 2 & 45 & 45 & 96 & 96 & 84 \\
\hline 3 & 42 & 60 & 150 & 150 & 144 \\
\hline 4 & 45 & 70 & 80 & 126 & 165 \\
\hline 5 & 30 & 72 & 31,5 & 84 & 160 \\
\hline 6 & 45 & 70 & 135 & 168 & 105 \\
\hline 7 & 30 & 60 & 120 & 122 & 150 \\
\hline 8 & 36 & 48 & 150 & 120 & 132 \\
\hline 9 & 45 & 80 & 150 & 72 & 126 \\
\hline 10 & 56 & 70 & 100 & 84 & 160 \\
\hline 11 & 18 & 80 & 125 & 60 & - \\
\hline 12 & 30 & 45 & 87,5 & 90 & - \\
\hline $\mathrm{V}_{\text {ср }}$ со стандартным отклонением & $39,0 \pm 10,5$ & $65,0 \pm 13,3$ & $111,0 \pm 35,1$ & $104,0 \pm 33,4$ & $133,0 \pm 27,8$ \\
\hline$V_{t} / V_{t-1}$ & 1,0 & 1,7 & 1,7 & 0,9 & 1,3 \\
\hline
\end{tabular}

\section{Результаты}

Показано, что имплантация клеток меланомы линии mel Cher (нулевой пассаж) приводит к появлению солидных пальпируемых окрашенных в темно-коричневый цвет опухолевых узлов под кожей бока $100 \%$ мышей-самок Balb/c nude только после прививочной дозы $1,0 \times 10^{7}$. На 10-й день роста (латентная фаза) $\mathrm{V}_{\mathrm{cp}}=39,0 \pm 10,5$ мм $^{3}$. Затем опухоли росли медленно без существенной динамики и экспоненциального роста, достигая к 24-м суткам $\mathrm{V}_{\mathrm{cp}}=133,0$ $\pm 27,8$ мм $^{3}$. Кратность еженедельного прироста опухоли менее $2: \mathrm{V}_{\mathrm{t}} / \mathrm{V}_{\mathrm{t}-1}=1,7-0,9-1,3$ (табл. 1, рис. 1).

На 4-м пассаже кинетика роста опухолей прогрессивно изменялась: латентная фаза сократилась до 8 дней, появилась экспоненциальная фаза длительностью до 14 дней, а к 21-м суткам $\mathrm{V}_{\text {ср }}=1526,3 \pm$ 496,0 мм ${ }^{3}$, что в 10 раз превысило размеры нулевого пассажа. Достигнутая кинетика роста опухоли устойчиво сохранялась до 9-го пассажа со стабильными временными характеристиками. Прослеженная до окончания наблюдения кинетика роста mel Cher под кожей мышей при трансплантации 50 мг взвеси на мышь прогрессивно менялась после 4-го пассажа параллельно нарастанию пигментации до черного цвета. От 4-го до 9-го пассажа: латентная фаза составляла 8 дней с выходом опухолей на уровне $\mathrm{V}_{\mathrm{cp}}=61 \pm 25 \mathrm{мm}^{3}$; экспоненциальная фаза длилась 6 дней (до 14-х суток) с пиком на 11-е сутки на уровне $\mathrm{V}_{\mathrm{cp}}=182 \pm 67$ мм $^{3}$,

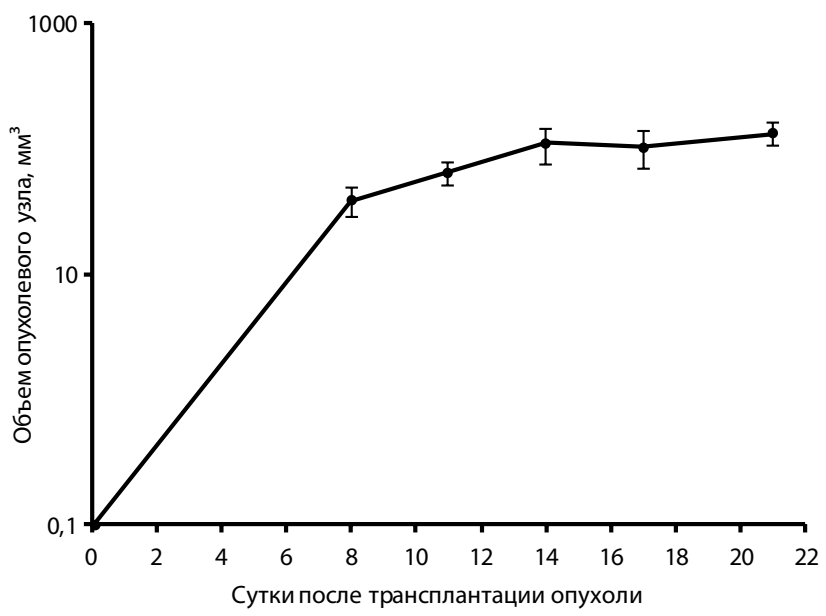

Рис. 1. Кинетика роста меланомных узлов (нулевой пассаж) под кожей бока мышей-самок Balb/c пиде после имплантации $1,0 \times 10^{7}$ клеток линии пигментированной меланомы кожи человека теl Cher

$\mathrm{V}_{\mathrm{t}} / \mathrm{V}_{\mathrm{t}-1}=2,9$; стационарная фаза продолжалась 10 дней на уровне $\mathrm{V}_{\mathrm{cp}}=1379 \pm 496 \mathrm{мм}^{3}$ (до 24-х суток), колебания $\mathrm{V}_{\mathrm{t}} / \mathrm{V}_{\mathrm{t}-1}=1,9-2,1-1,8$ (табл. 2, pис. 2).

Цитологически клеточный состав п/к ксенографтов 9-го пассажа идентичен исходной линии клеток пигментированной меланомы кожи человека mel Cher. Видно, что клеточный состав полиморфный и представлен клетками разных размеров и формы: вытянутой, удлиненной, отростчатой, веретеноообразной с тонкими длинными отростками разной длины, 
Таблица 2. Показатели роста меланомных узлов под кожей мышей-самок Balb/с пиде после трансплантации 50 мг взвеси меланомы кожи человека теl Cher (4-й и 9-й пассажи)

\begin{tabular}{|c|c|c|c|c|c|c|}
\hline \multirow{2}{*}{ Номер мыши } & \multicolumn{5}{|c|}{ Средний объем меланомных узлов после трансплантации, мм³ } & \multirow{2}{*}{$\begin{array}{l}\text { Пигмен- } \\
\text { тация +/- }\end{array}$} \\
\hline & на 8-е сутки & на 11-е сутки & на 14-е сутки & на 17-е сутки & на 21-е сутки & \\
\hline \multicolumn{7}{|c|}{ 4-й пассаж } \\
\hline 1 & 80 & 215 & 650 & 840 & 1989 & + \\
\hline 2 & 100 & 280 & 480 & 1092 & 2160 & + \\
\hline 3 & 96 & 260 & 420 & 1530 & 2002 & + \\
\hline 4 & 40 & 350 & 468 & 1200 & 1430 & + \\
\hline 5 & 40 & 165 & 336 & 924 & 1950 & + \\
\hline 6 & 40 & 140 & 280 & 800 & 1358 & + \\
\hline 7 & 81 & 176 & 392 & 720 & 950 & + \\
\hline 8 & 96 & 180 & 336 & 560 & 976 & + \\
\hline 9 & 35 & 112 & 231 & 616 & 1638 & + \\
\hline 10 & 72 & 126 & 252 & 420 & 810 & + \\
\hline 11 & 42 & 128 & 312 & 297 & 1140 & + \\
\hline 12 & 40 & 140 & 343 & 576 & 1260 & + \\
\hline 13 & 40 & 140 & 245 & - & - & + \\
\hline 14 & 45 & 168 & 294 & 616 & 990 & + \\
\hline 15 & 70 & 156 & 245 & 504 & 648 & + \\
\hline $\mathrm{V}_{\text {ср }}$ со стандартным отклонением & $61 \pm 25$ & $182 \pm 67$ & $352 \pm 114$ & $763 \pm 333$ & $1379 \pm 496$ & \\
\hline$V_{t} / V_{t-1}$ & 1,0 & 2,9 & 1,9 & 2,1 & 1,8 & \\
\hline \multicolumn{7}{|c|}{ 9-й пассаж } \\
\hline 1 & 48 & 144 & 216 & 391 & 533 & + \\
\hline 2 & 40 & 126 & 216 & 364 & 520 & + \\
\hline 3 & 162 & 600 & 750 & 976 & 1260 & + \\
\hline 4 & 144 & 700 & 810 & 1137 & 1920 & + \\
\hline 5 & 118 & 364 & 795 & 876 & 890 & + \\
\hline 6 & 93 & 256 & 375 & 568 & 954 & + \\
\hline 7 & 79 & 196 & 275 & 369 & 732 & + \\
\hline 8 & 129 & 463 & 697 & 579 & 1168 & + \\
\hline 9 & 133 & 375 & 578 & 965 & 1053 & + \\
\hline 10 & 65 & 578 & 456 & 890 & 904 & + \\
\hline $\mathrm{V}_{\text {ср }}$ со стандартным отклонением & $101,1 \pm 13,4$ & $380,2 \pm 63,1$ & $516,8 \pm 65,3$ & $711,5 \pm 62,3$ & $993,4 \pm 154,0$ & \\
\hline$V_{t} / V_{t-1}$ & 1,0 & 3,8 & 1,4 & 1,4 & 1,4 & \\
\hline
\end{tabular}




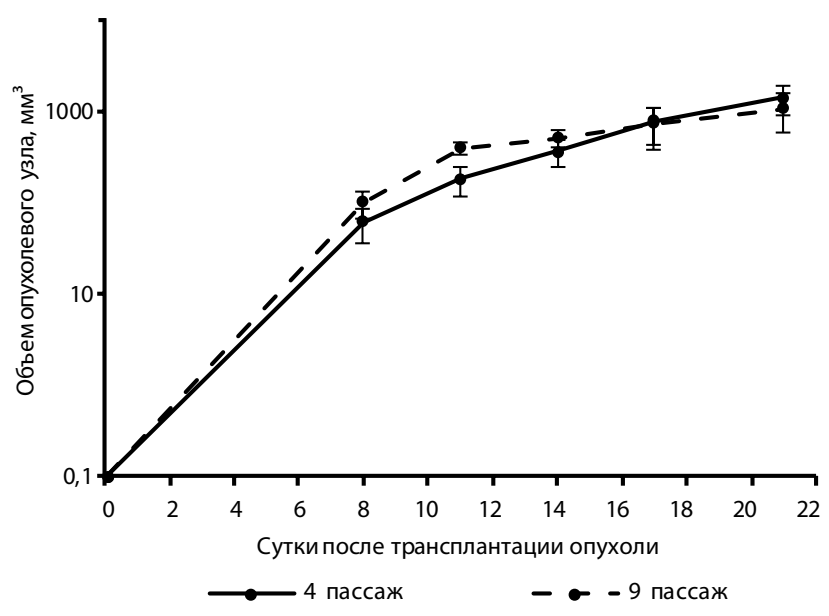

Рис. 2. Устойчивая кинетика роста опухолевых узлов пигментированной меланомы кожи человека теl Cher под кожей бока половозрелых мышей-самок Balb/c пиdе при многократном пассировании

округлой, овальной и неправильной формы. Цитоплазма клеток относительно обильная, негомогенная, окрашена в базофильные тона разной степени интенсивности, иногда с розоватым оттенком, и часто содержит значительное количество мелкозернистого пигмента меланина. Ядра опухолевых клеток полиморфные, нормо- и гиперхромные с 1-3 ядрышками. Строение хроматина мелкозернистое или мелкоглыбчатое. В части клеток отмечаются почкование и фрагментация ядер. Много уродливых гигантских многоядерных клеток округлой, вытянутой, удлиненной, отростчатой и неправильной формы с центральным или периферическим расположением ядер. Встречаются также гигантские 1-ядерные и 2-ядерные клетки. Часто выявляются митозы (рис. 3).

Данные трансплантационных исследований с патоморфологическим контролем позволяют считать завершенным процесс получения модели пигментированной меланомы кожи человека mel Cher в виде

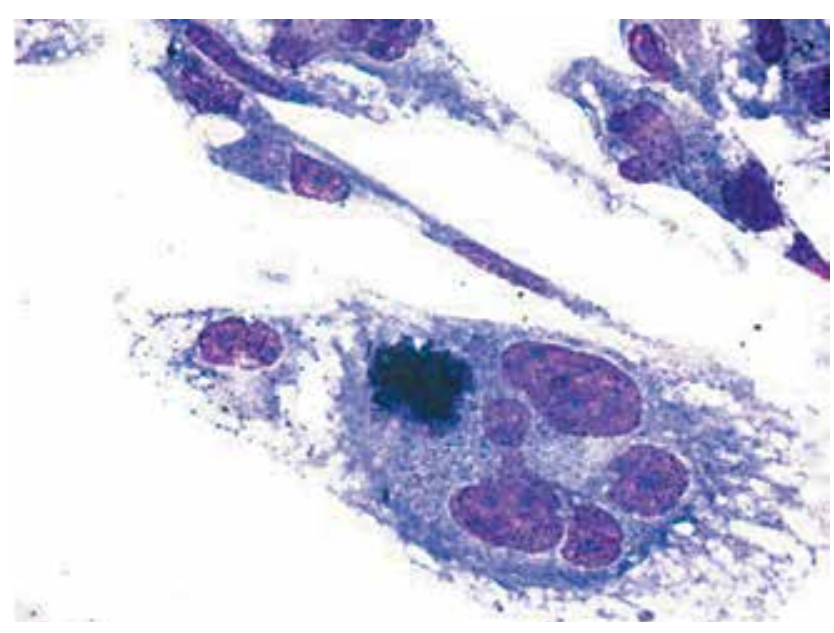

Рис. 3. Клеточный состав пигментированной меланомы кожи человека теl Cher (окраска гематоксилином и эозином, ×200) п/к ксенографтов у иммунодефицитных мышей-самок Balb/c nude.

В образце опухолевого узла меланомы кожи человека mel Cher 9-го пассажа на пике экспоненциальной фазы роста выявлена мутация V600E BRAF.

Результат секвенирования ПЦР-продукта с мутацией V600E BRAF в ДНК, выделенной из клеток п/к узла mel Cher, показан на рис. 4 и 5.

\section{$a$}
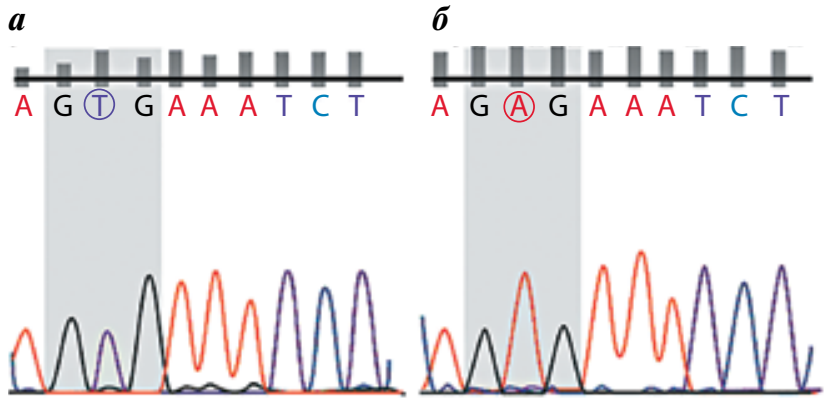

Рис. 4. Схема анализа мутации V600E BRAF в подкожных ксенографтах меланомы кожи человека теl Cher 9-го пассажа у мышей Balb/c nиde: (a) - дикий тип, (b) - мутация с. $1799 T>A$, приводящая к замене валина на глутаминовую кислоту в позиции 600 (V600Е), триплет $G T G$ à $G A G$ выделен полосой

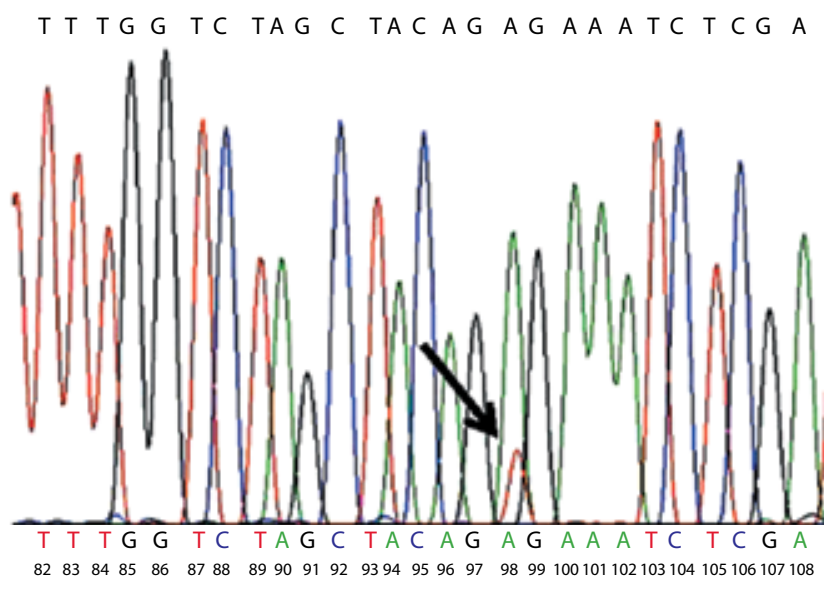

Рис. 5. Сиквенс 15-го экзона гена BRAF, ДНК из клеток подкожных ксенографтов меланомы кожи человека теl Cher 9-го пассажа у мышей Balb/c nude, мутация $1799 T>A(G T G->G A G)$ выделена стрелкой

Полученные нами п/к ксенографты оказались высокочувствительными к таргетной терапии вемурафенибом. При длительной пероральной терапии на фоне непрерывного прогрессивного увеличения объема опухолей в контроле вемурафениб на протяжении всего курса полностью ингибировал рост опухоли. После отмены препарата в течение 7 дней регистрировалась полная ремиссия, а затем наступил рецидив, скорость роста опухоли соответствовала контрольной кривой в период ранней экспоненты (рис. 6).

Данные молекулярно-генетического и химиотерапевтического исследований позволяют считать модель mel Cher в виде п/к ксенографтов у иммунодефицитных 


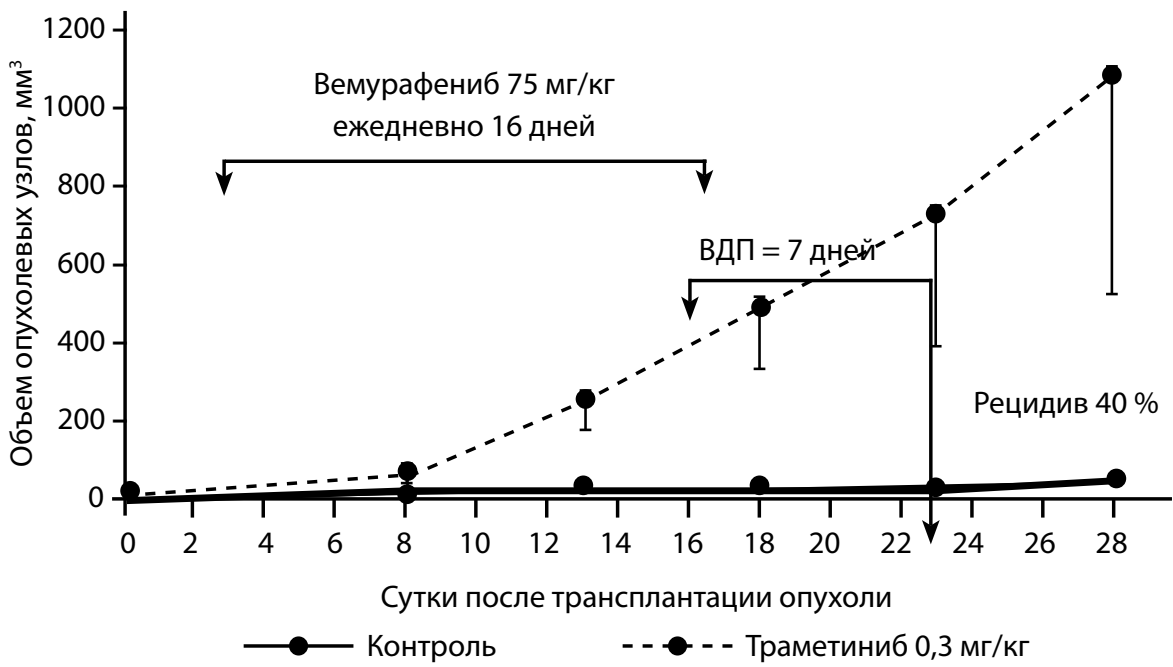

Рис. 6. Чувствительность подкожных ксенографтов меланомы кожи человека теl Сhег клечению ингибитором ВRAF-киназы вемурафенибом, ВДП - время до прогрессирования.

мышей Balb/c nude новым штаммом пигментированной меланомы кожи человека, чувствительной к ингибиторам BRAF-киназы.

\section{Заключение}

В результате адаптации к росту под кожей иммунодефицитных мышей-самок Balb/c nude клеточной линии пигментированной меланомы кожи человека с мутацией V600E BRAF, mel Cher с определенной проспективно мутацией V600E BRAF получена новая перевиваемая модель меланомы in vivo в виде п/к ксенографтов.
Основные характеристики ксенографта: идентичность клеточного состава линии mel Cher, устойчивая кинетика роста на 4-9-м пассажах (латентная фаза 8 дней, экспоненциальная - до 14, стационарная - до 24), наличие мутации V600E BRAF.

Показана чувствительность п/к ксенографтов mel Cher к таргетной терапии вемурафенибом (зельборафом) с достижением 7-дневной полной ремиссии и рецидивирующим течением.

Модель предложена для доклинического изучения соответствующих указанной мишени таргетных противомеланомных средств.

\section{J И T E P A T}

1. Вишневская Я.В., Машенкина Я.А., Сендерович А.И. и др. Современная морфологическая, иммуногистохимическая и молекулярно-генетическая диагностика меланомы кожи. Сибирский онкологический журнал 2012;4(52): 74-5. 2. Демидов Л.В., Орлова К. В. Индивидуализация лекарственного лечения меланомы кожи. Практическая онкология 2013;14(4):239-46.

3. Bollag G., Hirth P., Tsai J. et al. Clinical efficacy of a RAF inhibitor needs broad target blockade in BRAF-mutant melanoma. Nature 2010;467:596-9.

4. Flaherty K.T., Puzanov I., Kim K.B. et al. Inhibition of mutated, activated BRAF in metastatic melanoma. N Engl J Med 2010;363:809-19.

5. Joseph E.W., Pratilas C.A., Poulikakos P.I. et al. The RAF inhibitor PLX4032 inhibits ERK signaling and tumor cell proliferation in a V600E BRAF-selective manner. Proc Natl Acad Sci U S A 2010;107(33):14903-8.
6. Tsai J., Lee J.T., Wang W. et al. Discovery of a selective inhibitor of oncogenic B-Raf kinase with potent antimelanoma activity. Proc Natl Acad Sci USA 2008; 105:3041-6. 7. Benlloch S., Paya A., Alenda C. et al. Detection of BRAF V600E mutation in colorectal cancer comparison of automatic sequencing and real-time chemistry methodology. J Mol Diagn 2006;8:540-3. 8. Ribas A., Kim K. B., Schuchter L.M. et al. BRIM-2: an open label, multicenter phase II study of vemurafenib in previously treated patients with BRAF V600E mutation positive melanoma. J Clin Oncol 2011; 29(15 Suppl):8509.

9. Walker G.J., Soyer H.P., Terzian T., Box N.F. Modelling melanoma in mice. Pigment Cell Melanoma Res 2011;24:1158-76. 10. Михайлова И.М., Барышников А.Ю. Коллекция клеточных линий меланомы человека. Издательство НИИ ЭДиТО ФГБУ «РОНЦ им. Н.Н. Блохина» Минздрава России 2016:107.
11. Патент РФ № 2364624. Клеточная линия меланомы человека mel Cher, используемая для получения противоопухолевых вакцин. Михайлова И.Н., Барышников А.Ю., Демидов Л.В., Киселев С.Л., Бурова О.С., Морозова Л.Ф. 2009. 12. Трещалина Е.М. Иммунодефицитные мыши разведения РОНЦ им. Н.Н. Блохина РАМН. Возможности использования. М., 2010.

13. Патент РФ № 2572569. Способ получения подкожных ксенографтов клеточной линии меланомы кожи человека mel Cher с мутацией V600E $B R A F$ для доклинического изучения таргетных противоопухолевых средств. 2015.

14. Трешалина Е.М., Андронова Н.В., Гарин А.М. Доклиническое изучение противоопухолевых препаратов. В кн.: Рациональная фармакотерапия в онкологии. М.: Litterra, 2015. С. 75-82. 